giảm nhân thức làm tăng 12,5 lần nguy cơ sảng. Đây là yếu tố có giá trị tiên lượng sảng rượu, có ý nghĩa thống kê $p<0,05$ [7]. Trong nghiên cứu của Berggren và cộng sự(2009) cho thấy tiền sử bênh nhân có co giât do rượu thì nguy cơ sẽ tăng 4,0 lần có ý nghĩa thống kê với $p<0,05$ [8].

\section{KẾT LUÂNN}

Biểu hiện lâm sàng của trạng thái cai rượu chủ yếu là các triệu chứng cơ thể. Đánh giá lâm sàng cận lâm sàng và tiền sử các rối loạn tâm thần do rượu có vai trò quan trọng trong tiên lượng biến chứng sảng run và co giật do rượu.

\section{TÀI LIÊU THAM KHẢO}

1. WHO (2014). Global status report on alcohol and health, 2014, Geneva.

2. Nông Thế Đoàn (2018), Đánh giá hiêu quả lâm sàng phác đồ điêu trị phối hợp Diazepam và Phenobarbital trong điều tri hôi chứng cai rươu, Luân văn thạc sĩ y học, Trường Đ̇ai hoc y Hà Nội.

3. Hoàng Văn Trong (2004). Đắc điểm các hình thái lâm sàng loạn thần do rượu tại viện Sức khỏe
Tâm thân, Luận văn Thạc sĩ y học, Trường Đại học y Hà Nôi.

4. Phạm Thế Văn (2019), "Nghiên cứu đặc điểm lâm sàng và tiến triển cúa hội chứng cai rượu ở bênh nhân điều tri nôii trú tai Viên sức khỏe tâm thần", Luận văn thạc sĩ y học, Trường Đại học y Hà Nội.

5. Rafael Monte et al (2009), "Risk factors for delirium tremens in patients with alcohol withdrawal syndrome in a hospital setting", abstracts from 8th congress of European Federation of internal medicine/ European journal of internal medicine 20S, S1 - S283.

6. Eyer Florian, et al (2011). Risk assessment of moderate to severe alcohol withdrawal - predictors for seizure and delirium tremens in the course of withdrawal. Alcohol and Alcoholism, vol. 46, No. 4, pp. 427 - 433

7. Sukanto Sarkar et al (2017), risk factor for the development of delirium in alcohol dependence syndrome: clinical and neurobiological implication, Indian journal of psychiatry, vol 59, issue 3, 300-305.

8. Berggren U, Fahlke $C$, Berglund K.J et al. (2009). Thrombocytopenia in Early Alcohol Withdrawal is Associated with Development of Delirium Tremens or Seizures. Alcohol and Alcoholism, 44(4), 382-386.

\title{
ĐÁNH GIÁ THỰC TRANG LIỆU PHÁP TẬP THỞ Ở BỆNH NHÂN CHẤN THƯƠNG NGỰC CÓ DẪN LƯU MÀNG PHỔI TAII TRUNG TÂM TIM MẠCH VÀ LỒNG NGỰC - BÊ̂NH VIÊ̂N HỮU NGHI VIỆT ĐỨC
}

\section{TÓM TẮT}

Đắt vấn đề: Lý liệu pháp hô hấp (bao gồm liệu pháp tâp thở) là một can thiêp điều tri bắt buộc sau phẫu thuật lồng ngực cũng như sau chấn thương ngực có dẫn lưu màng phổi, có ý nghĩa rất quan trọng giúp nhanh chóng đây đờm dãi, máu ra khỏi đường hô hấp, chống xẹp phổi, giúp phổi nở sát thành ngực, góp phần đẩy hết máu - khí ra khỏi khoang màng phổi. Nghiên cứu này nhằm đánh giá thực trạng sự tuân thủ thực hiên liêu pháp với người bênh sau chấn thương ngực có dẫnl lưu màng phổi trong thời gian gần đây. Phương pháp: Nghiên cứu mô tả cắt ngang-tiến cứu: kết quả nghiên cứu ghi nhận ở các biến số: tuổi, giới tính, tổn thương kèm theo thưc trang tuân thủ thực hiễn liệu pháp tập thở... Số liệu được thu thập theo mẫu bểnh án nghiên cứu cho từng bểnh nhân và xử lý bằng chương trình SPSS 20.0. Kết quả: Từ tháng 6/2020 đến $11 / 2020$ có 98 bệnh nhân chấn thương

${ }^{1}$ Đai hoc Y Hà Nội

${ }^{2}$ Bệnh viện Hữu nghi Việt Đức

${ }^{3}$ Bềnh viện đa khoa Hà Đông

Chịu trách nhiệm chính: Pham Hữu Lư

Email: phamhuulu@hmu.edu.vn

Ngày nhận bài: 12.7.2021

Ngày phản biên khoa hoc: 6.9.2021

Ngày duyệt bài: 14.9.2021
Phạm Hữu Lư ${ }^{1,2}$, Đoàn Văn Thuỷ ${ }^{3}$

ngức có dẫn lưu màng phổi được lựa chon vào nhóm nghiên cứu với tỷ lệ thực hiện đúng đủ các bước của liểu pháp tâp thổi bóng $76 \%$, tiếp theo liệu pháp thở chúm môi là $46 \%$, liệu pháp tập thở cơ hoành có tỷ lệ $27 \%$. Kết luân: Liêu pháp tấp thở là một liệu pháp quan trọng trong chăm sóc bệnh nhân chấn thương ngực có dẫn lưu màng phổi.

Tư khóa: Liệu pháp tập thở, chấn thương ngực, phẫu thuật lồng ngực.

\section{SUMMARY \\ EVALUATION OF BEATHINHG EXERCISE THERAPY IN THORACIC TRAUMA \\ PATIENTS WITH CHEST DRAIN AT CARDIOVASCULAR \& THORACIC CENTER -} VIET DUC UNIVERSITY HOSPITAI

Background: Chest physiotherapy (including breathing exercises therapy) is a mandatory treatment intervention after thoracic surgery as well as after chest trauma with pleural drainage, which is very important to help quickly expel phlegm, blood out of the respiratory tract, prevent lung collapse, help the lungs expand close to the chest wall, contributing to pushing all the blood - air out of the pleural cavity. This study aims to evaluate the status of adherence to therapy with patients after recent chest trauma with pleural drainage. Methods: Cross-sectional- 
progressive descriptive study: the research results were recorded in the variables: age, sex, associated lesions, compliance status with breathing exercises... Data were collected according to patient samples. Research project for each patient and processed by the SPSS 20.0 software. Results: From June 2020 to November 2020, 98 chest trauma patients with pleural drainage were selected to be included in the study group with the rate of correctly performing all steps of balloon training therapy $76 \%$, followed by therapy pursed-lip breathing is $46 \%$, diaphragmatic breathing therapy has a rate of $27 \%$. Conclusion: Breathing exercise therapy is a very important therapy in the care of patients with chest trauma after surgery to drain the lungs.

Keyword: Breathing exercise therapy, thoracic trauma, thoracic surgery

\section{I. ĐặT VẤN ĐỀ}

Chấn thương ngực là tổn thương nặng gây ảnh hưởng trực tiếp đến hô hấp và tuần hoàn có thể dẫn đến tử vong nhanh chóng nên đây là loại cấp cứu được ưu tiên số một trong chẩn đoán, vận chuyển và xử trí [1]. Ngoài phương pháp điều trị ngoại khoa cơ bản là dần lưu màng phổi, cần phải làm tốt liệu pháp tập thở nhằm hổ trợ đẩy dịch, khí trong khoang màng phổi ra ngoài giúp phổi nở tốt. Trong điều trị sau phẫu thuât lồng ngực nói chung và sau dẫn lưu màng phổi do chấn thương ngực nói riêng thì lý liệu pháp hô hấp (trong đó có liệu pháp tập thở LPTT) chiếm vai trò quan trọng của chăm sóc sau mổ [2], [3]. Tại trung tâm Tim mạch và Lồng ngực - Bệnh viện hữu nghị Việt Đức chúng tôi đã và đang tiến hành liệu pháp này thường xuyên mang lại nhiều ưu điểm cho người bệnh nhưng chưa có nhiều nghiên cứu cụ thể về vấn đề này. Vì vậy chúng tôi tiến hành nghiên cứu này nhằm đánh giá thực trạng sự tuân thủ thực hiện LPTT đối với người bệnh sau mổ chấn thương ngực có DLMP trong thời gian gần đây.

\section{II. ĐỐI TƯợNG VÀ PHƯƠ'NG PHÁP NGHIÊN CỨU}

Phương pháp nghiên cứu: Nghiên cứu mô tả cắt ngang- tiến cứu

Đối tượng nghiên cứu:

Tiêu chuẩn lựa chọn: Bao gồm những bệnh nhân chấn thương ngực đã được dẫn lưu màng phổi với điều kiện bệnh nhân trên 15 tuổi không phân biệt tuổi - giới, tỉnh táo - tiếp xúc tốt (thang điểm Glasgow 15 điểm), bệnh nhân đồng ý tham gia nghiên cứu.

Tiêu chuẩn loại trư: Những trường hợp bệnh nhân có bệnh lý về tâm thần, chấn thương ngực đã chỉ định mở ngực xử trí tổn thương, bệnh nhân không đồng ý nghiên cứu

Các biến số dự kiến: Kết quả nghiên cứu nghi nhận ở các biến số: tuổi, giới tính, tổn thương đơn thuần, tổn thương phối hợp, thực trạng thực hiện LPTT

Xử lý số liệu: Số liệu được nghi nhận vào mẫu bệnh án nghiên cứu cho từng bệnh nhân và xử lý bằng chương trinh SPSS 20.0

\section{KẾT QUẢ NGHIÊN CỨU}

Từ tháng 6/2020 đến 11/2020 có 98 trường hợp chấn thương ngực có dẫn lưu màng phổi với tỷ lệ nam chiếm $79,6 \%$ và $20,4 \%$ là nữ. Tuổi thấp nhất là 16; cao nhất 85 tuổi. Tuổi trung binh 47,5 $\pm 15,5$.

Bảng 1. Loại tôn thương trong chấn thương ngực lúc vào viện $(n=98)$

\begin{tabular}{|c|c|c|}
\hline Loại chà́n thương & $\mathbf{n}$ & $\mathbf{\%}$ \\
\hline Tràn máu màng phổi đơn thuần & 69 & 70,4 \\
\hline Tràn khí màng phối đớn thuần & 6 & 6,1 \\
\hline Tràn máu - tràn khí màng phổi & 23 & 23,5 \\
\hline Tổng & $\mathbf{9 8}$ & $\mathbf{1 0 0}$ \\
\hline
\end{tabular}

Nhận xét: Phần lớn người bệnh vào viện với chẩn đoán tràn máu khoang màng phổi $(70,4 \%)$, tiếp theo là chẩn đoán phối hợp tràn máu, tràn khí màng phổi $(23,5 \%)$.

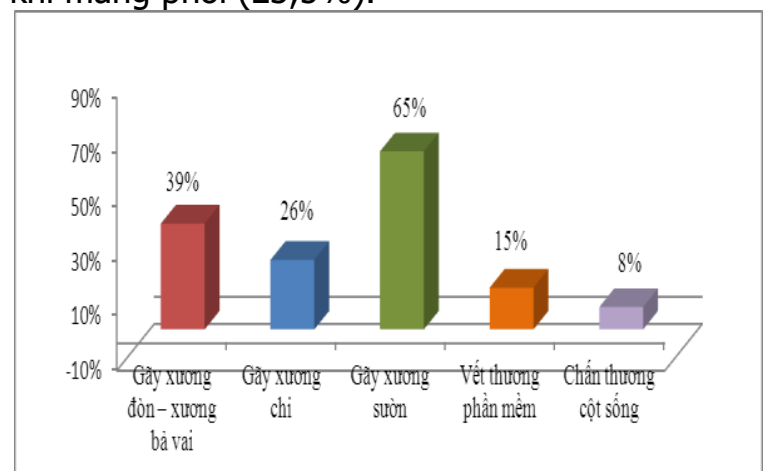

Biểu đồ 1. Tổn thương kèm theo $(n=98)$

Nhận xét: Gãy xương sườn là tổn thương kèm theo hay gặp nhất chiếm $65 \%$, tiếp theo là tổn thương gãy xương đòn và xương bả vai chiếm 39\%.

Bảng 2. Sốlượng tôn thương kèm theo $(n=98)$

\begin{tabular}{|c|c|c|}
\hline Số lượng tốn thương & $\mathbf{n}$ & $\mathbf{\%}$ \\
\hline 1 tốn thương & 62 & 63,3 \\
\hline$\geq 2$ loại tô̂́n thương & 36 & 36,7 \\
\hline Tống & $\mathbf{9 8}$ & $\mathbf{1 0 0}$ \\
\hline
\end{tabular}

Nhận xét: Tỷ lệ người bệnh chỉ có đơn thuần 1 tổn thương chiếm chủ yểu $(63,3 \%)$.

Bảng 3. Thực trạng thực hiện các kĩ thuật trong liệu pháp tập thơ $(n=98)$

\begin{tabular}{|c|c|c|}
\hline Lieệu pháp tập thơ & $\mathbf{n}$ & $\mathbf{\%}$ \\
\hline Tập thở chúm môi & 98 & 100 \\
\hline Tập thở cơ hoành chủ động & 96 & 98 \\
\hline Tập thở bằng thối bóng & 96 & 98 \\
\hline
\end{tabular}


Nhận xét: Có 2 người bệnh không tham gia liệu pháp tập thở cơ hoành chủ động và 2 người bệnh không tham liệu pháp tập thở bằng thổi bóng.

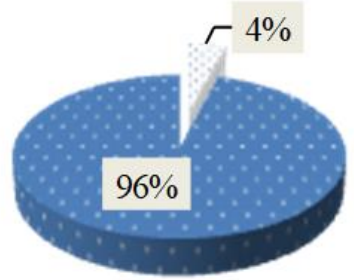

Thực hiện không đủ 3 liệu pháp " Thực hiện đủ 3 liệu pháp

Biểu đồ 2. Tinh trạng thực hiện liệu pháp tập thơ $(n=98)$

Nhận xét: Phần lớn người bệnh thực hiện cả 3 liệu pháp tập thở trong nghiên cứu với tỷ lệ $96 \%$.

Bảng 4. Thực trang thực hiện đúng các bước trong liệu pháp tập thở chúm môi $(n=98)$

\begin{tabular}{|c|c|c|}
\hline Liệu pháp tập thở chúm mối & $\mathbf{n}$ & $\mathbf{\%}$ \\
\hline Bước 1 (Ngồi tư thế thoải mái) & 74 & 75,5 \\
\hline Bước 2 (Hít vào chậm qua mũi) & 88 & 89,8 \\
\hline $\begin{array}{c}\text { Bước 3 (Môi chúm lại như huýt sáo, } \\
\text { thở ra bằng miệng sao cho thời gian } \\
\text { thở ra gấp đồi thời gian hít vào) }\end{array}$ & 65 & 66,3 \\
\hline Đúng cả 3 bước & 45 & 45,9 \\
\hline
\end{tabular}

Nhận xét: Tỷ lệ người bệnh thực hiện đúng bước 2 chiếm tỷ lệ cao nhất $(89,8 \%)$

Bảng 5. Thực trạng thực hiện đúng các bước liệu pháp tập thở cơ hoành chủ động $(n=96)$

\begin{tabular}{|c|c|c|}
\hline Liệu pháp tập thở cơ hoành & $\mathbf{n}$ & $\%$ \\
\hline Bước 1 (Ngồi tư thễ thoải mái) & 71 & 74 \\
\hline $\begin{array}{c}\text { Bước } 2 \text { (Đặt tay nhẹ lên thành } \\
\text { bụng) }\end{array}$ & 70 & 72,9 \\
\hline $\begin{array}{l}\text { Bước } 3 \text { (Hít vào từ từ qua mũi } \\
\text { bệnh nhân cảm thây thành bụng } \\
\text { căng ra và đẩy bàn tay họ ra) }\end{array}$ & 39 & 40,6 \\
\hline $\begin{array}{c}\text { Bước 4 (Thở ra chậm, mím môi lại } \\
\text { cho hơi thở từ tữ qua kẽ môi bụng } \\
\text { xẹp dần xuống) }\end{array}$ & 69 & 71,9 \\
\hline Đúng cả 4 bước & 26 & 26,5 \\
\hline
\end{tabular}

Nhận xét: Tỷ lệ người bệnh thực hiện đúng bước 1 và 2 trong liệu pháp tập thở chiếm tỷ lệ cao nhất $(74 \%$ và $72,8 \%)$.

Bảng 6. Thực trang thực hiện các bước trong liệu pháp tập thở thổi bóng $(n=96)$

\begin{tabular}{|c|c|c|}
\hline $\begin{array}{c}\text { Liệu pháp tấp thở thối bóng } \\
\text { Bước 1 (Ngồi cân đối hoặc tư thế } \\
\text { nưaa nằm nửa ngồi) }\end{array}$ & $\mathbf{n}$ & $\mathbf{\%}$ \\
\hline Bước 2 (Hít sâu qua mũi hết sức) & 92 & 89,6 \\
\hline $\begin{array}{c}\text { Bước 3 (Thổi mannh và hết vào } \\
\text { bóng đá đến khi bóng căng) }\end{array}$ & 94 & 97,9 \\
\hline Bước 4 (Số lần thổi bóng giàm & 86 & 89,6 \\
\hline
\end{tabular}

\begin{tabular}{|c|l|l|}
\hline dần tới 2 lần hoặc ít hơn) & & \\
\hline Đúng cả 4 bước & 73 & 76 \\
\hline
\end{tabular}

Nhận xét: Tỷ lệ người bệnh thực hiện đúng bước 2 và 3 trong liệu pháp tập thở chiếm tỷ lệ cao nhất với $(95,8 \%$ và $97,9 \%)$.

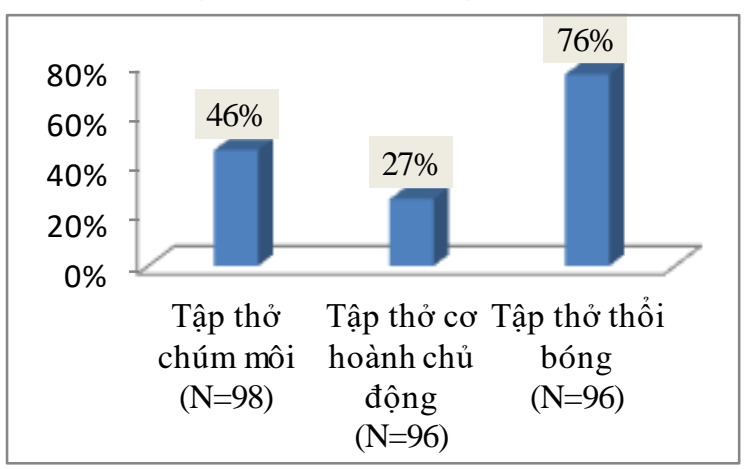

Biểu đồ 3. Thực trạng thực hiện đúng tất cả các bước trong các liệu pháp tập thở

Nhận xét: Tỷ lệ người bệnh thực hiện đúng tất cả các bước trong liệu pháp tập thở thổi bóng chiếm tỷ lệ cao nhất với (76\%).

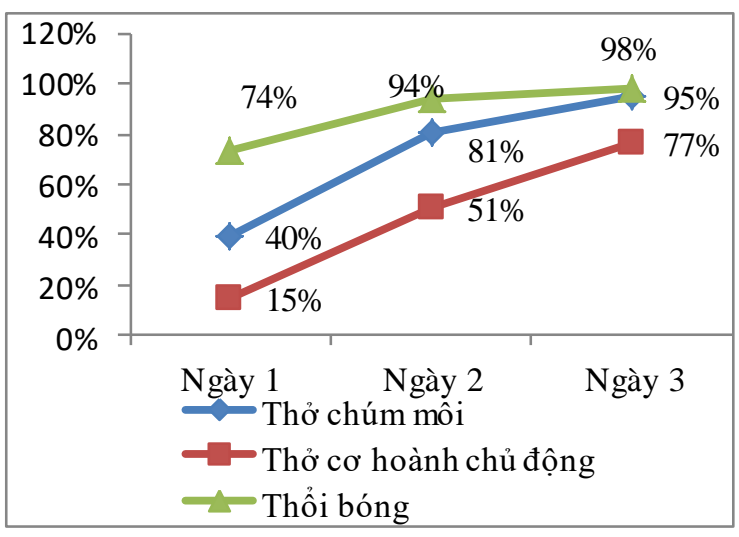

Biểu đồ 4. Thực trạng tuân tuân thủ thực hiện các liệu pháp tập thở $(n=98)$

Nhận xét: Liệu pháp tập thở thổi bóng có tỷ lệ tuân thủ ở cả ba ngày đều đạt tỷ lệ cao nhất.

\section{BÀN LUẬN}

Đặc điểm chung: Nghiên cứu trên 98 bệnh nhân cho thây nam giới chiếm tỷ lệ $79,6 \%$ chủ yếu nằm trong độ tuổi lao động trong đó nhóm tuổi từ 16-60 tuổi trong nghiên cứu của chúng tôi là $78,6 \%$.

Một số đặc điểm tổn thương: Kết quả của chúng tôi cho thây phần lớn là tràn máu màng phổi chiếm 70,4\% (Bảng 1). Tổn thương kèm theo hay gặp nhất là gãy xương sườn $65 \%$ (Biểu đồ 1$)$. Vũ Thùy Linh và cs (2010) trên 110 bệnh nhân chấn thương ngực ở bệnh viện hữu nghị Việt Đức cho thây các tổn thường đi kèm rất đa 
dạng trong đó có 33,9\% thủng thành ngực, gãy xương chi là $23,9 \%$, chấn thương sọ não là $6,1 \%$, chấn thương cột sống thắt lưng là $2,6 \%$ [4].

Thực trạng thực hiện liệu pháp tập thở. Các can thiệp vật lý trị liệu hổ hấp đã được mô tả trong một số nghiên cứu gồm các bài tập thở sâu, liệu pháp khí dung, phương pháp ho chủ động và đo chức năng hô hấp tích cực [2], [7]. Trong nghiên cứu của chúng tôi có $100 \%$ đối tượng nghiên cứu đồng ý thực hiện liệu pháp tập thở chúm môi, tỷ lệ người bệnh tham gia liệu pháp tập thở cơ hoành và tập thở bóng là $98 \%$. Tỷ lệ người bệnh tham gia thực hiện cả 3 liệu pháp tập thở là $96 \%$. Mỗi liệu pháp tập thở đều có những ưu và nhược điểm riêng. Việc phối hợp thực hiện cả 3 liệu pháp tập thở sẽ giúp đối tượng nghiên cứu khắc phục được những nhược điểm của riêng mỗi liệu pháp tập thở, đồng thời mang lại được những lợi ích tổi ưu của nó, các liệu pháp tập thở khác nhau giúp tăng cường hiệu quả điều trị và nhanh chóng hồi phục sức khỏe.

Thực trạng thực hiện liệu pháp tập thở chúm môi: Qua quá trình quan sát các bước thực hiên liệu pháp tập thở trên ở đối tượng nghiên cứu cho thấy tỷ lệ bệnh nhân thực hiện đúng tất cả các bước trong liệu pháp chiếm 46\% (Bảng 4). Việc thực hiện không đúng các bước trong liệu pháp tập thở chúm môi, có thể sẽ làm giảm hiệu quả của liệu pháp. Nguyễn Thị Vân (2016) nghiên cứu trên 50 bệnh nhân chấn thương ngực cho thấy tỷ lệ thực hiện tập thở chúm môi chiếm $10 \%$, kết quả nghiên cứu cho thấy trong số 8 lượt quan sát chỉ có $2 / 8$ lượt tập đủ các bước, $100 \%$ người bệnh thực hiện sai liệu pháp thở chúm môi [5].

Thực trạng thực hiện liệu pháp tập thở cơ hoành chủ động: Tỷ lệ thực hiện đúng các Bước 1, Bước 2, Bước 4 lần lượt là: $74 \%, 72,9 \%$ và $71,9 \%$. Tỷ lệ đối tượng nghiên cứu thực hiện đúng cả 4 bước trong liệu pháp thấp chỉ chiểm $27 \%$ (Bảng 5), có thể là do 65,3\% đối tượng nghiên cứu có tổn thương gãy xương sườn đi kèm. Do vậy, khi tập thở bằng liệu pháp này có thể gây đau cho đổi tượng nghiên cứu dẫn đến tỷ lệ thực hiện đúng các bước trong liệu pháp này đạt tỷ lệ thấp hơn so với thở chúm môi. Hellen van Aswegen và cộng sự [8] cho thấy các liệu pháp can thiệp hô hấp thường được sử dụng hơn gồm có các kỹ thuật thở chủ động với $83 \%$, bài tập thở sâu với 94\%, ho chủ động với 96\%, kỹ thuật thở ra cưỡng bức với $94 \%$, đi lại và định vị cơ thể để tăng cường thông khí và tưới máu. Bởi vậy, các bệnh nhân chân thương ngực lớn thường được điều trị chủ yếu với các bài tập thở và vận động nhưng hiếm khi có các can thiệp về quản lý cớn đau. Phục hồi chức năng sau xuất viện cũng rất ít.

Thực trạng thực hiện các bước trong liệu pháp tập thở thổi bóng:Tập thở thổi bóng là một liệu pháp tập thở mà người bệnh khi tập thở cần sử dụng thêm ruột quả bóng đá nhằm lượng hoá quá trình tập thở. Các bước người bệnh thực hiện liệu pháp tập thở thổi bóng bao gồm 4 Bước như Bảng 6 trong đó tỷ lệ thực hiện đúng cả 4 bước trong liệu pháp thối bóng là $76 \%$. Tỷ lệ thực hiện đúng cao tất cả các bước trong liệu pháp thổi bóng có thể là do các bước thực hiện trong liệu pháp đơn giản và dễ dàng thực hiện. Nguyễn Thị Vân (2016) cho thây tỷ lệ người bệnh tập thổi bóng $96 \%$, tổng số lượt quan sát người bệnh người bệnh tập thở thổi bóng là 48 lượt trong đó có chỉ có 7 lượt thực hiện đủ các bước, 41 lượt tập thiếu các bước và có 33/48 lượt người bệnh tập sai kỹ thuật [5]. Kết quả nghiên cứu của Vũ Thùy Linh (2010) tỷ lệ tập thổi bóng chiếm 100\% [4].

Vấn đề tuân thư liệu pháp tập thở. Nghiên cứu của chúng tôi áp dụng theo khuyến nghị mỗi liệu pháp tập thở nên được luyện tập từ 2 lần trong ngày và mỗi lần luyện tập liệu pháp tập thở từ 5 đến 10 phút. Điều này cũng được nêuu trong một số nghiên cứu [4], [5]. Những bệnh nhân báo cáo thực hiện liệu pháp tập thở nào từ 2 lần trở lên trong ngày và mỗi lần thực hiện tối thiểu 5 phút sẽ được chúng tôi đánh giá là tuân thủ điều trị. Kết quả nghiên cứu của chúng tôi cho thấy: Tỷ lệ tuân thủ thực hiện các liệu pháp tập thở hô hấp tăng dần từ ngày thứ nhất đến ngày thứ 3 sau khi vào viện. Liệu pháp tập thở thổi bóng có tỷ lệ tuân thủ ở cả ba ngày đều đạt tỷ lệ cao nhất. Tỷ lệ tuân thủ liệu pháp tập thở cơ hoành tại cả 3 ngày đều đạt tỵ lệ thấp hớn so với 2 liệu pháp tập thở còn lại. Tỷ lẹ̉ tuân thủ thực hiện liệu pháp tập thở thổi bóng cao hơn so với tỷ lệ tuân thủ liệu pháp tập thở cơ hoành và liệu pháp tập thở chúm mồi có thể được giải thích là do: Thứ nhất là trong nghiên cứu của chúng tôi có $65 \%$ bệnh nhân chấn thương ngực có tổn thương gãy xương sườn đi kèm, tổn thương khác như gãy xương đòn, xương bả vai, xương chi chiếm $36,7 \%$ nên việc thực hiện các bước trong liệu pháp tập thở cơ hoành sẽ gặp nhiều khó khăn về việc thực hiện đúng tư thế khi tập thở; Thứ hai là tập thở bằng cơ hoành có thể gây đau các cơ quan bộ phận tổn thương khác, dấn đến tình trạng tuân thủ tập luyện liệu pháp tập thở cơ hoành trong nghiên cứu của chúng tồi thấp hơn so với 2 liệu 
pháp tập thở còn lại. Nghiên cứu của chúng tôi cũng cho thấy, mặc dù liệu pháp tập thở chúm môi và liệu pháp tập thở thổi bóng có nguyên lý thực hiện khá tương tự nhau, nhưng kết quả nghiên cứu lại cho thây liệu pháp tập thổi bóng lại có tỷ lệ đối tượng nghiên cứu tuân thủ cao hơn. Điêuu này có thể được giải thích là do ở liệu pháp tập thở thổi bóng người bệnh có thể luyện tập ở cả 2 tư thế là ngồi tập và nằm tập, trong khi ở liệu pháp tập thở chúm môi người bệnh cần phải thực hiện ở tư thế ngồi. Bởi vậy, người bệnh có xu hướng thực hiện luyện tập thở thổi bóng nhiều hơn, tuân thủ hướng dẫn tốt hơn để đạt được kết quả điều trị tốt nhất. Kết quả nghiên của một số tác giả đã cho thấy tỷ lệ cao người bệnh thực hiện liệu pháp tập thở bằng thổi bóng trong điêu trị chấn thương ngực [5]. Theo Aswegen $\mathrm{H}$ van: Các bài tập chức năng và các bài tập thở sâu có tính chất giảm đau do vậy can thiêp vật lý trị liệu là một phần chăm sóc và điều trị bệnh nhân chấn thương ngực làm giảm tỷ lệ xẹp phổi, viêm phổi... và rút gắn thời gian nằm viện. Bên cạnh đó, việc tuân thủ điều trị, chi phí điều trị, tỉ lệ sống sau chấn thương, và chất lượng cuộc sống của bệnh nhân cũng cần được quan tâm. [3].

\section{KẾT LUẬN}

Kết quả nghiên cứu đã phản ánh thực trạng việc triển khai và thực hiện liệu pháp tập thở với bệnh nhân chấn thương ngực có dấn lưu màng phổi. Liệu pháp tập thở có vai trò chính trong thực hiện các bước của lý liệu pháp hô hấp, đòi hỏi phải được thực hiện thường xuyên, liên tục, tăng dần theo sự dung nạp của bệnh nhân để đạt được kết quả điều trị tốt nhất.

\section{TÀI LIÊU THAM KHẢO}

1. Nguyễn Hữu Ước (2006), Khám chấn thương vết thương ngực, Bài giảng triệu chứng học ngoại khoa, Nhà xuất bản Y học, tr.90-102.

2. Fishman AP. (1996), The chest physician and physiatrist: perspectives on the scientific basis of pulmonary rehabilitation and related research. In: Bach JR, ed. Pulmonary rehabilitation: the obstrauctive and paralytic conditions. Philadelphia: Hanley \& Belfus, 1-1.

3. Aswegen $\mathrm{H}$ van (2020). Physiotherapy management of patients with trunk trauma: A state-of-the-art review. S Afr Physiother.76(1),1406: $1-8$

4. Vũ Thùy Linh (2010), Nhân xét quy trình chăm sóc dẫn lưu khoang màng phổi trên bệnh nhân chấn thương, vết thương ngực tai khoa phẫu thuât Tim mạch- Lồng ngực bệnh viện hữu nghị Việt Đức Hà Nội, Luân văn tốt nghiệp cử nhân y khoa, Trường Đại học Y Hà Nội.

5. Nguyễn Thị Vân (2016). Nhận xét tình hình thức hiên lý liêu pháp hô hấp ở bênh nhân chấn thương, vết thương ngực tai bệnh viện hữu nghi Việt Đức, Luận văn tốt nghiệp cứ nhân y khoa, Đại học Y Hà Nội.

6. Nguyễn Thị Vân (2013), Đánh giá kết quả chương trình phưc hồi chức năng hô hấp cho bênh nhân dày dính màng phổi sau phẫu thuật bóc vỏ màng phổi, Luân Văn Thạc sĩ y học, Đại học Y Hà Nội.

7. Alfred F. Connors; Willy E Hammon (1980), Chest Physical Therapy: The immediate effect on oxygenation in acutely III patients. In: Chest Physical Therapy. Chest J, 78: 559-564.

8. Aswegen $H$ van, Reeve J, Beach $L$, Parker $R_{\text {, }}$ Olsèn MF (2020). Physiotherapy management of patients with major chest trauma: Results from a global survey. Trauma. 2020;22(2): 133-141.

\title{
KẾT QUẢ TRUNG HÂN ĐĂT GIÁ Đỡ TRONG ĐIỀU TRI TẮC ĐộNG MACH CHÂ̂U MAN TÍNH TỔN THƯƠNG TASC II A, B
}

\author{
Lê Đức Tín*, Phạm Minh Ánh*, Đỗ Kim Quế**
}

\section{TÓM TẮT}

Mục tiêu: Đánh giá kết quả trung hạn đặt giá đõ trong điều trị tắc động mạch châu man tính tổn thương TASC II A, B. Phương pháp: Hồi cứu mô tả. Kết quả: Nghiên cứu có 90 bênh nhân, can thiêp được 110 chi, nam chiếm $90 \%$, tuổi trung bình 68,6 \pm

\author{
*Bênh viện Chơ Rẫy \\ **Bêenh viên Thống Nhất \\ Chịu trách nhiệm chính: Lê Đức Tín \\ Email: ductin@ump.edu.vn \\ Ngày nhận bài: 12.7.2021 \\ Ngày phản biên khoa hoc: 6.9.2021 \\ Ngày duyệt bài: 14.9.2021
}

10,3. Can thiệp chậu chung chiếm 44,4\%, chậu ngoài chiếm $37,8 \%$; chậu chung và chậu ngoài phối hợp có $17,8 \%$ trường hợp. Can thiệp hai chi $21,1 \%$, tâng chậu đơn thuân $45,6 \%$, phối hợp các tâng dưới chậu là $54,4 \%$ trường hợp. Thời gian nằm viện trung bình là $4,8 \pm 3,1$ ngày. Thời gian can thiệp trung bình $147,9 \pm 56,4$ phút. Biến chứng chung có $4 \%$, trong đó tắc mach $2,2 \%$, nhồi máu cơ tim $1,1 \%$, cắt cut $2,2 \%$ mấu nghiên cứu. Kết quả thành công về mặt kỹ thuật chiếm $100 \%$, thành công về mặt lâm sàng ở giai đọan trung hạn là 85,1\%. Kết luận: Phương pháp đặt giá đõ nội mạch điêuu trị tắc động mach chậu mạn tính tổn thương TASC II A, B là ít xâm lấn, an toàn, hiệu quả, ít biến chứng, thời gian nằm viên ngắn, hổi phục nhanh. Kết quả theo dõi trung hạn đạt tỷ lệ thành 